\title{
An Research of Gamification Impact in Learning Mathematics
}

\author{
N. H. Z. Abidin, S. Ahmad, M. A. Kardri, N. L. Saad
}

\begin{abstract}
Interactive teaching has become a trend since digital technology is more update nowadays. Educators need to upgrade their style of teaching by integrating technology in their conventional teaching. It is important to create a more motivated and fun lesson for the student, especially when teaching Mathematics. Even Mathematics is important; some may have difficulty learning it. One of the alternative methods used to solve the problems in teaching mathematics is a game-based learning instrument. A game-based learning on indices and logarithm have been developed and introduced to a group of undergraduate students. The game development framework is explained thoroughly step by step. This paper presents the gamification impact on learning indices and logarithm where the empirical data was obtained from the gamified and control group. The student's perception is also supported by an assessment done on the Mathematics topic.
\end{abstract}

Keywords: Gamification, Interactive, Mathematics, Perception.

\section{INTRODUCTION}

Interactive learning is now becoming a trend, as today's learners are digital natives and have grown up using digital technologies. Therefore, it becomes a challenge for practitioners who are still using conventional taught in learning practices. It is because there are having difficulties in keeping students motivated and engaged especially in Mathematics. In modern pedagogical, Information Communication Technology (ICT) must be integrated into the teaching lesson [1]. Therefore, virtual learning such as gaming is a way to motivate and engaged student in learning Mathematics in an interesting manner.

In a conventional lesson, the practitioners are unable to satisfy all individual learners as each of them have a different level of understanding and assistant required [2]. Education institutions are told to be fascinated in gamification of education as it does encourage the learners to learn mathematics in a fun and interesting manner [3]. The

Revised Version Manuscript Received on September 16, 2019.

N. H. Z. Abidin, Department of Mathematical Sciences, Faculty of Computer and Mathematical Sciences, Universiti Teknologi MARA, Perak Branch, Tapah Campus, 35400 Tapah Road, Perak, Malaysia \& Universiti Putra Malaysia, 43400 UPM, Serdang, Selangor, Malaysia.

S. Ahmad, Department of Computer Science, Faculty of Computer an Mathematical Sciences, Universiti Teknologi MARA, Perak Branch, Tapah Campus, 35400 Tapah Road, Perak, Malaysia \& Institute for Mathematical Research, Universiti Putra Malaysia, 43400 UPM, Serdang, Selangor, Malaysia.

M. A. Kardri, Department of Mathematical Sciences, Faculty of Computer and Mathematical Sciences, Universiti Teknologi MARA, Perak Branch, Tapah Campus, 35400 Tapah Road, Perak, Malaysia, Universiti Putra Malaysia, 43400 UPM, Serdang, Selangor, Malaysia.

N. L. Saad, Department Computer Science, Faculty of Computer and Mathematical Sciences, Universiti Teknologi MARA, Perak Branch, Tapah Campus, 35400 Tapah Road, Perak, Malaysia \& Institute for Mathematical Research, Universiti Putra Malaysia, 43400 UPM, Serdang, Selangor, Malaysia. emergence of gaming technologies is also presented in other research since gamification is generally known to give a good impact to the education industry [2]-[4].

A research done by [5] shows that, with the support of electronic collaborative learning environment, students have better attitudes towards learning Mathematics. They also viewed it as a motivation tool since the player collaboration and multi-player feature helps them to build the interaction between players and build up their motivation in learning Mathematics.

In [2], [6], [7] had done research specifically in learning Mathematics at different level of education. In [2] has introduced MathDungeon as a game tool in learning mathematical concepts on Algebra among college students. This game tool emphasizes the concepts and exercises to learners with variety of options. The gamification also can be implemented using MOOC model where the Moodle techniques are introduced [4]. These methods are created in separate modules and blocks, which can be used completely in gamification, such as group use, status bar, badges and quizzes. However, Moodle e-learning tools are required online and skilled and experienced educators are needed in developing the modules that suitable for the course.

Besides that, an instructional model was introduced by [7] where they used E-book software and Kahoot tools. The improvised method proposed a better explanation, assignments and quizzes through online and mobile application. These tools encourage learners and students to interact efficiently during the course. Even though these techniques are interactively developed, but it can only be applied to assess the learners in exam based oriented but cannot measure the outcome of the course. Therefore, the present study has developed a game study in a Mathematics topic where the concepts, applied, quizzes and challenges are implied in the game development. Hence, a study on the game impact on learners is done based on observation and experience.

\section{METHODOLOGY}

To achieve the learning outcome, developing an efficient approach to implement gamification in learning mathematics is essential. Fig. 1 presents the conceptual framework. 


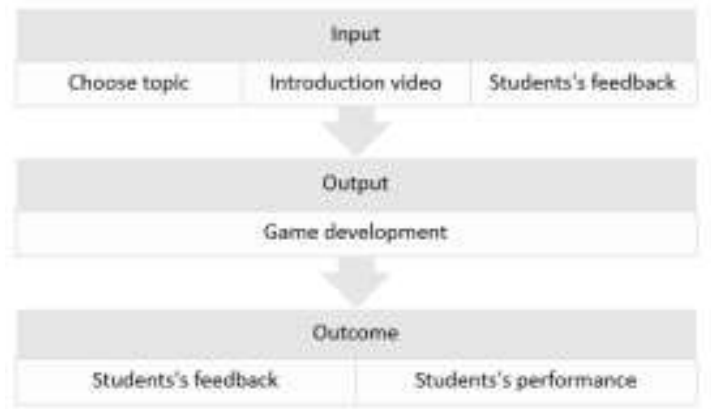

Fig. 1: Conceptual framework

Input

The first stage is to determine the suitable Mathematics topics. The selection was chosen based on the topic difficulty and a quick survey from first semester diploma students. The 'indices and logarithm' topic is selected for our game development project. This topic is covered in the Pre-Calculus subject and this subject is taken by several courses as a pre-requisite to other Mathematics or Computer Sciences subject. The decision is also taken by referring to the final exam result where it shows that students have difficulties to answer the topic completely since they have to memorize few properties to solve indices and logarithm problem.

After selecting the topic, the next step is developing an introduction video based on the topic and this video is being evaluated by the first semester diploma's students. This video serves as a benchmark for the criteria for creating a successful teaching tool in the topic of mathematics teaching. The rate scores are from 1 to 4 where score 1 represents 'below standard', score 2 represents 'needs improvement', score 3 represents 'satisfactory' and score 4 represents 'excellent'. The observation item is text, graphic, music, duration, pace of delivery and the content. The technical criterion is shown in Table 1.

Authors have published their finding in [8] where the students can accept video as a teaching tool in learning Mathematics. The student's reaction and remarks along with the results from the video assessment are taken as a guide to the development of game-based learning.

Table 1: Interface and technical video evaluation (\%)

\begin{tabular}{|c|c|c|c|c|}
\hline Item & $\begin{array}{c}\text { Below Standard } \\
\text { Score: } \mathbf{~}\end{array}$ & $\begin{array}{c}\text { Needs Improvement } \\
\text { Score: } \mathbf{2}\end{array}$ & $\begin{array}{c}\text { Satisfactory } \\
\text { Score: 3 }\end{array}$ & $\begin{array}{c}\text { Excellent } \\
\text { Score: } \mathbf{4}\end{array}$ \\
\hline Text & 0 & 5.9 & 35.3 & 58.8 \\
\hline Colour & 0 & 2 & 47.1 & 50.9 \\
\hline Music & 0 & 11.8 & 47.1 & 50.9 \\
\hline Duration & 0 & 11.8 & 51 & 37.3 \\
\hline Pace of delivery & 0 & 6 & 48 & 46 \\
\hline Content & 0 & 2 & 45.1 & 52.9 \\
\hline Overall performance & 0 & 3.9 & 43.1 & 53 \\
\hline
\end{tabular}

Authors have published their finding in [8] where the students can accept video as a teaching tool in learning Mathematics. The student's reaction and remarks along with the results from the video assessment are taken as a guide to the development of game-based learning.

\section{Output}

The earlier research was done by [2] state that the gaming approach for higher education failed due to artistic animation tools that are not attractive in the lessons. This indicates the importance of the introduction video that was implemented in the first stage. The interactive video is not only to get the basic idea to develop the game but indirectly can be used in class to introduce the properties of indices and logarithms.

However, those approaches did not fully engage the student in experiencing the concepts and theory of Mathematics as a whole. It is because, to develop a game which simple, fun and easy in Mathematics is cumbersome for developer and learners. Furthermore, some of the game setting also lacks scaffolding for learners and is not appealing to learners [2], [9]. Therefore, mechanics, dynamics and aesthetic (MDA) framework has been used to design the gamification for learning indices and logarithms.

The framework was proposed by [10] where MDA supports a formal, interactive approach to design, tuning and able to give impact on the game development. In order to gamify the concepts of Mathematics, the learners have to associate the gaming element aspects. A game based on the topic of indices and logarithms was developed by authors where several elements have been used in designing the game such as rewarding, challenging, status and competition. The screenshot of the developed game is shown in Fig. 2. There are several elements have been used in designing the game.

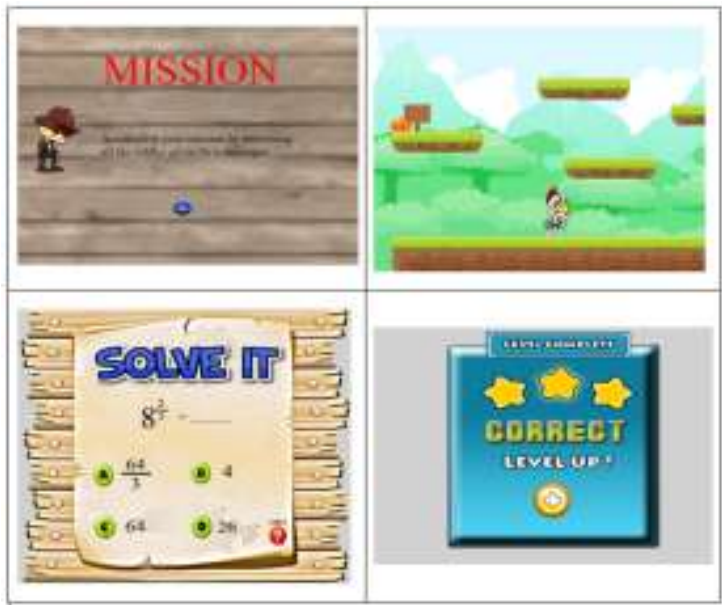

Fig. 2: Screenshot of game development 
Rewarding element is applied as an intention to influence the learner's behavior to repeat playing the game [11], [12]. The score will be given in the form of points. This element appreciates the work of students based on their achievement. Three levels (easy, medium and difficult) comply with the challenging element. Each level has different types of difficulty and student can build up their confidence. The third element is status where player is given a status representing their performance such as beginner, amateur or as an expert [1], [12]. Students can build their motivation as they earn some recognition, fame and respect from others. Students can also challenge themselves to compete with the other competitors in accomplishing each level. This affects the learners more excitement to learn mathematics in fun and interesting approaches.

The game has been developed based on those elements to provide an interesting approach where learning indices and logarithm becomes easy and fun. Besides, the gamification framework created is associated with non-game elements where it also provides learning materials through video animation, to make sure students can understand the conceptual and rules of indices and logarithm, before they proceed with playing the game. In the game prototype, the introduction video produced earlier wasused.

\section{RESULTS AND DISCUSSION}

In order to prove the effectiveness of the gamified project, the developed game was introduced to a group of students ( $\mathrm{N}$ =70). The earlier introduction video is also implemented in the game development. However, students are given the option of whether to view or skip the introduction video. As the introduction video focuses more on the properties and some simple examples, the game will focus more on the exercises and challenge the student's understanding.

The lecturer will start to introduce the topic of indices and logarithm to a control group $(\mathrm{N}=70)$ as they learn the topic conventionally, whereas another one group learn the topic independently by introduction video provided and through games. The students will self-learning the topics and keep practicing (playing) on the exercises.

After the time given, these two groups were tested with a set of question papers on the related topics. Few questions were arranged randomly to avoid any discrepancy on the questions. However, questions are set at the same difficulties level.

To ensure that the gamifies approach benefit the educational process, two methods were obtained which are the online survey where students in the gamification approach group evaluate the satisfaction on the activity and the academic performance by all the students.

\section{A. Student's feedback}

All students from the gamification approach group must complete 10 questions online survey at the end of the session. Every question, as shown in Table 2, had a similar scale to the online survey done earlier to rate the introduction video. The scales are from Score 1 (Strongly Disagree) to 4 (Strongly Agree).

The first stage results were being used in the game development. Question 1 is being asked to indicate whether the game can attract students to start playing the game. Most students agree $(61 \%)$ that the video is attractive and user-friendly. However, we believe that the game can be enhanced for commercialization in the future since students still enjoy playing the game several times.

Students can highly motivate to learn Mathematics through game-based learning (62\%) and spending more time to do some revision for their own goods. Mathematics is known as a boring and difficult subject for a weak student but with a different approach in learning Mathematics, there will be no more to face such a problem.

From Table 2, we found that some of the students disagree with the challenging level $(10 \%)$ and duration of the game $(11 \%)$ but most of them satisfied with the challenging level and duration of the game. Further, $6 \%$ of the students responded that not all subjects that they wish to have a gaming approach, this is because of the different suitability of each subject. Some of them prefer to play the game offline instead online $(14 \%)$ whereby getting online all the time is limited.

Students strongly agree that from the games, they will learn a lot on the topic (58\%), enhanced the problem-solving skills $(61 \%)$ and earning score in the game makes their selfconfidence raise $(65 \%)$. Besides that, the students strongly prefer to play the game online instead offline $(60 \%)$ because their score will regularly update to compete with each other, not only in the same institution but other institution too. 
Table 2: Student's feedback on the gamification approach (\%)

\begin{tabular}{|c|c|c|c|c|c|}
\hline No. & Question & $\begin{array}{c}\text { Strongly Disagree } \\
\text { Score: } 1\end{array}$ & $\begin{array}{l}\text { Disagree } \\
\text { Score: } 2 \\
\end{array}$ & $\begin{array}{c}\text { Agree } \\
\text { Score: } 3\end{array}$ & $\begin{array}{l}\text { Strongly } \\
\text { Agree: } 4\end{array}$ \\
\hline 1 & The interface of the game is attractive and user friendly. & 0 & 0 & 39 & 61 \\
\hline 2 & The game is fun and enjoyable. & 0 & 0 & 42 & 58 \\
\hline 3 & I am motivated to learn the indices and logarithm topic & 0 & 0 & 38 & 62 \\
\hline 4 & The game is challenging & 0 & 10 & 48 & 42 \\
\hline 5 & The duration of game is satisfactory. & 0 & 11 & 52 & 37 \\
\hline 6 & I learn a lot on this topic by playing the games. & 0 & 0 & 42 & 58 \\
\hline 7 & Earning score in the game makes my self-confidence raise. & 0 & 0 & 35 & 65 \\
\hline 8 & I wish all subjects have game like this. & 0 & 6 & 45 & 49 \\
\hline 9. & The game enhances my problem-solving skills. & 0 & 0 & 39 & 61 \\
\hline 10. & I prefer to play the game online instead offline. & 0 & 14 & 26 & 60 \\
\hline
\end{tabular}

\section{B. Student's performance}

A set of questions were given before and after the learning process. Different sets were given in both test but with the same difficulty. Table 3 shows the outcomes acquired from the experiment. The outcome demonstrates that in both subjects, learners achieved better outcomes. In the subject of indexes, for instance, learners who score between 1 and 49 dropped from $35 \%$ to $9 \%$. In other words, this topic's failure rate is smaller. The average score of $50-79$ fell from $45 \%$ to $25 \%$ and the outstanding score of $80-100$ fell from $20 \%$ to $66 \%$. The findings in logarithms are better compared to indices where the outstanding rating of 80-100 rise from $17 \%$ to $75 \%$. Similar findings have been shown in issues combining both indices and logarithmic characteristics where student's performance rises from $29 \%$ to $50 \%$. This shows that through the game, learners have learned and improved their knowledge of the subjects.

Table 3: Test results (\%)

\begin{tabular}{|c|c|c|c|c|c|c|}
\hline & \multicolumn{3}{|c|}{ Pre-Test } & \multicolumn{3}{c|}{ Post-Test } \\
\hline Marks & $1-4$ & $50-7$ & $80-10$ & $1-4$ & $50-7$ & $80-10$ \\
9 & 9 & 0 & 9 & 9 & 0 \\
\hline Indices & 35 & 45 & 20 & 9 & 25 & 66 \\
\hline Logarithm & 21 & 62 & 17 & 5 & 20 & 75 \\
\hline $\begin{array}{c}\text { Combinatio } \\
\mathrm{n}\end{array}$ & 40 & 31 & 29 & 13 & 37 & 50 \\
\hline
\end{tabular}

\section{CONCLUSION}

We have developed a game study in a Mathematics topic (indices and logarithm) that aims to help both lecturer and students in teaching and learning process to make it more efficient and interesting. Several conclusions can be drawn from this study are as follows:

- gamification will give benefit to the students in aspect to motivate themselves in self-learning environment within their own time and flexibility with the minimal guidance from the lecturer,

- students should be trained to be independent in learning any subjects within their own capabilities with learning subjects, and

- through gamification, students will boost their critical thinking and try to make an achievement that can satisfy themselves. activities that give them so much fun and enjoy learning the

\section{ACKNOWLEDGMENT}

Valuable remarks and suggestions from anonymous reviewers are highly valued and are gratefully honored the financial support obtained from Universiti Teknologi MARA on this work.

\section{REFERENCES}

1. P. Fotaris, T. Mastoras, R. Leinfellner, and Y. Rosunally, "Climbing up the leaderboard: An empirical study of applying gamification techniques to a computer programming class university of the West of England, School of Computing and Creative Technologies," Electron. J. e-Learning, 14(2), 2016, pp. 94-110.

2. U. Faghihi, A. Brautigam, K. Jorgenson, D. Martin, A. Brown, E. Measures, and S. Maldonado-Bouchard, "How gamification applies for educational purpose specially with college algebra," Procedia Comput. Sci., 41, 2014, pp. 182-187.

3. F. H. Nah, Q. Zeng, V. R, Telaprolu, A. P. Ayyappa, and B. Eschenbrenner, "Gamification of education: A review of literature," International conference on hci in business, 2014, pp. 401-409.

4. O. B. Gené, M. M. Núñez, and Á. F. Blanco, "Gamification in MOOC: Challenges, opportunities and proposals for advancing MOOC model," 2nd Int. Conf. Technol. Ecosyst. Enhancing Multicult., 2014, pp. 215-220.

5. G. Lopez-Morteo and G. López, "Computer support for learning mathematics: A learning environment based on recreational learning objects," Comput. Educ., 48(4), 2007, pp. 618-641

6. M. D. Kickmeier-Rust, E.-C. Hillemann, and D. Albert, "Gamification and smart feedback," Int. J. Game-Based Learn., 4(3), 2014, pp. 35-46, 2014.

7. B. M. McLaren, D. M. Adams, R. E. Mayer, and J. Forlizzi, "A computer-based game that promotes mathematics learning more than a conventional approach," Int. J. Game-Based Learn., 7(1), 2016, pp. 36-56.

8. N. H. Z. Abidin, M. A. Kardri, S. Ahmad, and N. L. Saad, "Technical criterion for an effective video in learning mathematics," Int. J. Acad. Res. Bus. Soc. Sci., 8(4), 2018, pp. 1120-1126.

9. K. Trujillo, B. Chamberlin, K. Wiburg, and A. Armstrong, "Measurement in learning games evolution: Review of methodologies used in determining effectiveness of math 
snacks games and animations," Technol. Knowl. Learn., 21(2), 2016, pp. 155-174.

10. R. Hunicke, M. Leblanc, and R. Zubek, "MDA: A formal approach to game design and game research," AAAI Workshop on Challenges in Game AI, 2004, pp. 1-5.

11. J. M. Randel, A. B. Morris, C. D. Wetzel, and B. V. Whitehill, "The effectiveness of games for educational purposes: A review of recent research," Simulation and Gaming., 23(3), 1992, pp. 261-276.

12. L. Da Rocha Seixas, A. S. Gomes, and I. J. De Melo Filho, "Effectiveness of gamification in the engagement of students," Comput. Human Behav., 58, 2016, pp. 48-63.

13. U. Mandl, A. Dierx, and F. Ilzkovitz, The effectiveness and efficiency of public spending. Technical report, Brussels: European Commission, 2008.

14. H. H. Tsai, J. Y. Peng, C. T. Chang, P. T. Yu, and K. C. Chiou, "Applying an ebook tool with lecturing function and a game-based student response system in flipped classroom for a seminar course," IEEE International Symposium Educational Technology, 2016, pp. 75-79.

15. I. Yildirim, "The effects of gamification-based teaching practices on student achievement and students' attitudes toward lessons," The Internet and Higher Education, 33, 2017, pp. 86-92. 